\title{
Electronic Structure of Hole-Conducting States in Polyprolines
}

\author{
Nicolas P.-A. Monney, Thomas Bally,* and Bernd Giese* \\ University of Fribourg, Chemin du Musée 9, CH-1700 Fribourg, Switzerland
}

\begin{abstract}
Electron transfer over long distances in proteins by a hopping process requires transient relay stations that can harbor charge and spin for a short time span. Certain easily oxidizable or reducible side chains may assume that role, but it has been shown that charge transport in peptides can also take place in the absence of such groups which implies that the peptide backbone provides for hopping stations. We have identified three different types of radical cation states in such peptides that are associated with significantly lower ionization potentials than those of the constituent amino acids, and which may thus serve as relay stations for hole transport. Which of these states is the most stable one depends on the nature and the conformation of the peptide. In contrast to $\alpha$-helices which, due to their high dipole moments, can only form stable radical cation states that are localized on the $\mathrm{C}$-terminal amino acids, polyprolines are capable of

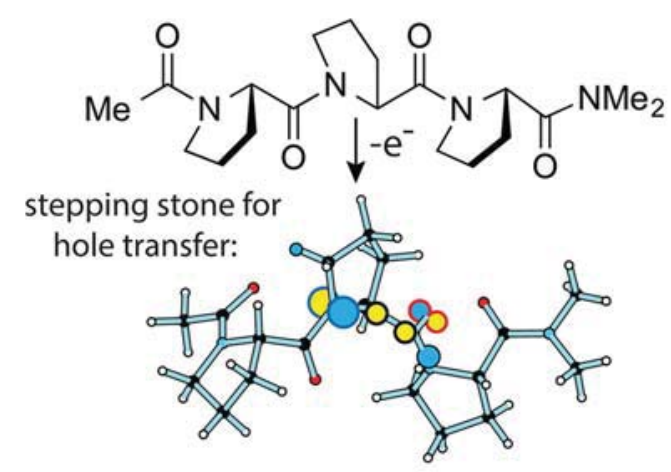
accommodating such states inside the PPII helices and those states may serve as relay stations for hole transfer through polyprolines. Of which type these states are depends often on small conformational changes, and sometimes the most stable states are hybrids of the three types we have identified.
\end{abstract}

\section{INTRODUCTION}

The transport of positive or negative charges over long distances is an essential function in living organisms. ${ }^{1-3}$ For distances greater than ca. $2 \mathrm{~nm}$, electron transfer in proteins can only occur in a multistep hopping process via "stepping stones" that are transiently oxidized or reduced during the process. $^{4,5}$ These relay stations allow one long and therefore very slow single step electron transfer to be divided into several short but quick steps which make that the rate of the electron transfer via multistep hopping decreases only slightly with the total distance between the electron donor and acceptor. ${ }^{6,7}$

Several protein side groups were shown to be able to act as stepping stones in the course of hole transfer in proteins. They can be divided into two groups, the aromatic moieties in tyrosine, tryptophan, and imidazole, and the sulfur containing side chains in cysteine or methionine. The efficiency of the first group to serve as stepping stones is due to their low oxidation or reduction potentials, respectively. ${ }^{8-10}$ Methionine on the other hand can only serve as a hole stepping stone if the oxidized sulfur lone pair is stabilized by a nearby aromatic or amide moiety. ${ }^{11-14}$ It was also shown that, even in the absence of the above-mentioned side groups, the backbones of $\alpha$ - and $3_{10}$-helices or $\beta$-turns can serve as relay stations. In the case of these structures, a large dipole moment decreases the oxidation potential especially at the C-termini of such structures. $^{6,15-17}$

Another secondary structure is the so-called PPII helix which is found in most peptides including electron transport proteins like cytochrome C551 of Pseudomonas aeruginosa or bacteriochlorophyll $\mathrm{A}$ in the photosynthetic bacterium
Prosthecochloris aestuarii. ${ }^{18}$ A major component of the PPII motif is the aliphatic amino acid proline, which does not contain an aromatic side chain or sulfur. ${ }^{19}$ The conformation of the PPII helix ${ }^{20}$ excludes a high dipole moment which therefore cannot serve to reduce the oxidation potential. ${ }^{21}$ However, we have recently shown that the backbone of proline within a peptide can stabilize a radical cation by the hyperconjugative effect. ${ }^{22}$ Therefore, we raised the question whether prolines could act as relay stations for electron hole tranfer through a PPII helix. In this paper, we investigate all possible interactions that stabilize a radical cation on the backbone of a peptide, and especially on a polyproline.

We chose a bottom-up approach to tackle this problem, by doing first calculations on glycine and proline terminated at the $\mathrm{N}$-terminus by an acetyl group and at the $\mathrm{C}$-terminus by an NHMe group, because in these compounds we could fully explore the conformational space of the neutral and radical cation and thus find and identify all possible hole-conducting states. We then extended our investigation to di- and triprolines, where a systematic conformational search was impossible for the radical cation, and was replaced by a rational search for the states that we had identified in the smaller model systems. Finally, we went for a hexaproline, the structure of which has recently been determined. ${ }^{20}$ Thus, we have been able to demonstrate that hole conduction through the backbone of polyprolines is possible. 


\section{METHODS OF CALCULATION}

All the calculations were performed with Gaussian $09^{23}$ using the M06-2X DFT functional ${ }^{24}$ together with the 6-31G* basis set, except for one set of calculations performed with the G4 method $^{25}$ that was made to validate the M06-2X method. This DFT functional was previously used to perform calculations on peptides and is thought to model the midrange correlation more accurately than the standard B3LYP method, at a slightly larger computational cost. Minima were confirmed by a vibrational analysis. The structures and molecular orbitals were visualized with the MOPlot program. ${ }^{26}$

\section{RESULTS AND DISCUSSION}

Ac-Gly-NHMe (1). In a previous paper, ${ }^{22}$ we demonstrated that the radical cation of the tripeptide PheProPhe can be

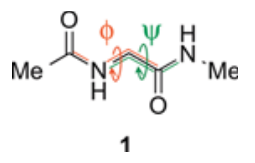

localized exclusively on its backbone. To gain more detailed insight into this phenomenon, we used the simple model compound, Ac-Gly-NHMe (1). A systematic relaxed scan was performed around the two Ramachandran angles $\phi$ and $\psi$ (depicted in red and green in the above scheme). Two equilibrium conformers were found in the neutral molecule, the first of which adopts a zigzag pattern, where $\phi$ and $\psi$ are close to $180^{\circ}$, and the second, $1 \mathbf{A}$, with $\phi=-84^{\circ}$ and $\psi=$ $68^{\circ}$ (see Table 1 ).

Table 1. Different Conformers of 1 with Their Relative Energies (in $\mathrm{kcal} / \mathrm{mol}$ ), Calculated with the M06-2X/631G* and G4 Methods

\begin{tabular}{lrrrr} 
& $\phi$ & $\psi$ & $\begin{array}{c}\text { M06-2X/6-31G* } \\
\text { relative energy }\end{array}$ & $\begin{array}{c}\text { G4 relative } \\
\text { energy }\end{array}$ \\
zigzag & \multicolumn{4}{c}{ Neutral } \\
$\mathbf{1 A}$ & 179 & 180 & 1.1 & 1.0 \\
& -84 & 68 & 0 & 0.0 \\
$\mathbf{1 A}^{\bullet+}$ & & Radical Cation & \\
$\mathbf{1 B}^{\bullet+}$ & -80 & 73 & 0.7 & 0.4 \\
$\mathbf{1} \mathbf{C}^{\bullet+}$ & -45 & 84 & 2.6 & 1.8 \\
$\mathbf{T S}$ connecting $\mathbf{1 A}^{\bullet+}$ & -57 & 142 & 0 & 0 \\
to $\mathbf{1 C}^{\bullet+}$ & 82 & 56 & 8.2 & 4.7 \\
\end{tabular}

Three minima were found on the potential energy surface of the radical cation of $\mathbf{1}$ (see Table 1), similar to those found previously. ${ }^{27,28}$ In conformer $1 \mathrm{~A}^{\bullet+}$, the spin is delocalized over an $(\mathrm{O}=\mathrm{C}) \mathrm{N}-\mathrm{C}_{\alpha}-\mathrm{CO}$ unit, in the same fashion as in several conformers of PheProPhe tripeptide we discussed previously. ${ }^{22}$ The shape of the singly occupied MO (SOMO) shows that the $\mathrm{C}_{\alpha}-\mathrm{C}$ bond serves as a hyperconjugative mediator for the through bond delocalization of the spin between the nonbonding $\pi$-HOMO of the C-terminal amide moiety and the in-plane p-AO of the carbonyl oxygen atom of the $\mathrm{N}$-terminal amide ( $\mathrm{cf}$. Figure 1). As a consequence, the $\mathrm{C}_{\alpha}-\mathrm{C}$ bond, along which the SOMO is bonding, is elongated from 1.52 to $1.69 \AA$.

In the second conformer, $\mathbf{1 B}^{\bullet+}$, which lies $1.9 \mathrm{kcal} / \mathrm{mol}$ above $1 \mathbf{A}^{\bullet+}$, the spin is delocalized by a 2-center-3-electron $(2 \mathrm{c}-3 \mathrm{e})$ through space interaction between the carbonyl oxygen atom of the $\mathrm{N}$-terminal amide and the nitrogen atom of the C-terminal amide. In order to maximize the overlap of the two interacting AOs, the C-terminal amide moiety is slightly twisted in $1 \mathbf{B}^{\circ+}$, thus sacrificing a part of the double bond character of the amide bond. This also reduces the N,Odistance to $2.2 \AA$.

In order to estimate the energy that is needed to twist an amide $\mathrm{C}-\mathrm{N}$ bond, we carried out model calculations on $\mathrm{N}$ acetylpyrrolidine. A rotational barrier of $17.8 \mathrm{kcal} / \mathrm{mol}$ was found for the neutral molecule, which is close to the 18.0 $\mathrm{kcal} / \mathrm{mol}$ measured by NMR spectroscopy, ${ }^{29}$ but this barrier drops to a mere $5 \mathrm{kcal} / \mathrm{mol}$ for the corresponding radical cation (Figure S1, Supporting Information). In $\mathbf{1 B}^{\bullet+}$, the dihedral angle between the $\mathrm{O}-\mathrm{C}-\mathrm{N}$ and the $\mathrm{H}-\mathrm{N}-\mathrm{Me}$ planes of the C-terminal amide is $17^{\circ}$, which, according to the energy profile of Figure S1 (Supporting Information), corresponds to an increase in energy of only $0.5 \mathrm{kcal} / \mathrm{mol}$, a low tribute to pay in order to maximize the $2 \mathrm{c}-3 \mathrm{e} \mathrm{N}: \mathrm{O}$ interaction. This interaction is further enhanced by localizing the spin on the $\mathrm{N}$ atom of the C-terminal amide, an effect that is due to the electron donating effect provided by the attached methyl group. This was confirmed by looking at the SOMO and spin densities in methylacetamide, that are essentially localized on the nitrogen atom, in contrast to acetamide where more of the spin is localized on the oxygen atom (Figure S2, Supporting Information).

The third conformer, $\mathbf{1 C}^{\bullet+}$, is characterized by a $2 \mathrm{c}-3 \mathrm{e}$ bond between the carbonyl oxygen atoms of the two amides (O. $\therefore$ O) that is only $2.1 \AA$ long. This state has been discussed in detail as a potential stepping stone in the electron hopping process in peptides. ${ }^{27,30,31}$

We also found a transition state between $1 \mathbf{A}^{\bullet+}$ and $1 \mathrm{C}^{\bullet+}$ that lies $8.2 \mathrm{kcal} / \mathrm{mol}$ higher than $1 \mathrm{C}^{\bullet+}(4.7 \mathrm{kcal} / \mathrm{mol}$ by G4). Unfortunately, no transition state was found that connects the latter two conformers to $\mathbf{1 B}^{\bullet+}$. All the M06-2X calculations gave similar energies as the wave function based highly correlated G4 method (see Table 1), which encouraged us to

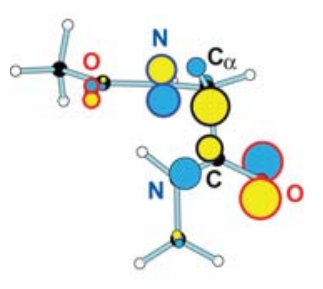

$1 \mathrm{~A}^{\cdot+}$

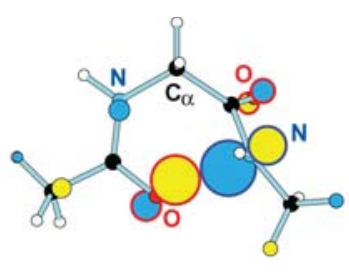

$1 \mathrm{~B}^{*+}$

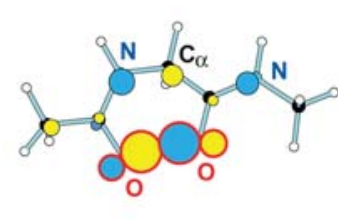

$1 \mathrm{C}^{\cdot+}$

Figure 1. Lowest energy conformers of the radical cation of 1 and their corresponding SOMOs. The lobes of the orbitals that are directly involved in the 3-electron interactions are highlighted (red-circled, AOs on oxygen; blue-circled, AOs on nitrogen; black-circled, AOs on carbon). 
keep using this functional for our investigations on oligoprolines.

Ac-Pro- $\mathrm{NMe}_{2}$ (2). To study the influence of a proline ring on the formation of the above-described radical cation states

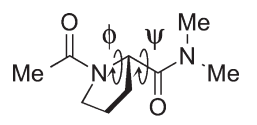

2

in a peptide, calculations were performed on the model compound, Ac-Pro-NMe $\mathrm{N}_{2}$ (2).

In the case of 2, a systematic conformational search revealed eight different conformers. The $\psi$ dihedral angle $(\mathrm{N}-$ $\mathrm{C}-\mathrm{C}-\mathrm{N}$ ) takes two different values, around 160 and $-40^{\circ}$, leading to conformers having the $\mathrm{NMe}_{2}$ group either tucked under the proline ring or pointing away from it. Each of these conformers can have the N-terminal amide in a cis or a trans conformation. As expected, the conformers with cis amide bonds are $2-4 \mathrm{kcal} / \mathrm{mol}$ higher in energy than the conformers where the amide bonds are trans (note that, unlike in other amino acids, cis-amide isomers are energetically quite accessible in prolines because the carbonyl group is facing a carbon atom in both diastereomers). The last parameter that influences the number of preferred conformers is caused by the flexibility of the proline ring which can assume two socalled "envelope conformations", where the tip of the ring points either toward the $\mathrm{C}$-terminal amide group or away from it, as illustrated in Figure 2 where the two conformers

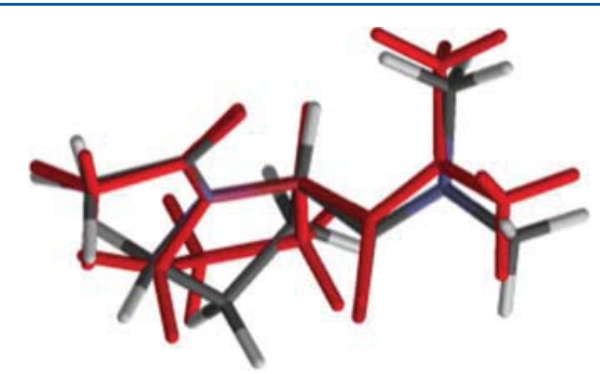

Figure 2. Superposition of the two conformers $2 \mathrm{~A}$ and $2 \mathrm{D}$ (in red).

$2 \mathrm{~A}$ and $2 \mathrm{D}$ are superimposed. Thus, although one reduces the flexibility of the peptide by introducing a proline, the number of degrees of freedom in the molecule increases, on the one hand because conformers with cis amide bonds become energetically accessible and on the other hand because the five-membered ring can adopt two envelope conformations. Table S1 (Supporting Information) summarizes the data for all the conformers that were found for neutral 2.

On one-electron oxidation of 2 , the number of conformers increases to 10 because, in addition to the structures obtained by optimizing the neutral conformers, two additional ones with a $2 \mathrm{c}-3 \mathrm{e}$ through-space $\mathrm{O} \therefore \mathrm{O}$ or $\mathrm{N}: \mathrm{O}$ interaction can be found (Table S2, Supporting Information). The four conformers of $2^{\bullet+}$ that are shown in Figure 3 and Table 2 are the lowest energy ones for each of the three different electronic states ("hyperconjugated" SOMO, through-space N.:O, and $\mathrm{O} \therefore \mathrm{O}$ interaction, respectively) plus a second conformer with a hyperconjugated SOMO, which has a different "envelope conformation" of the proline ring $\left(\mathbf{2 D}^{\circ+}\right)$. In the case of $2^{\circ+}$, the conformers with a hyperconjugated SOMO, $2 \mathrm{~A}^{\bullet+}$ and $2 \mathrm{D}^{\bullet+}$, are lower in energy than the conformers with a $2 \mathrm{c}-3 \mathrm{e}$ $\mathrm{N}: \mathrm{O}$ or $\mathrm{O} \therefore \mathrm{O}$ interaction, $2 \mathrm{~B}^{\bullet+}$ and $2 \mathrm{C}^{\bullet+}$, respectively. The

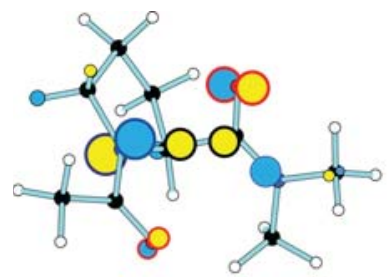

$2 A^{\cdot+}$

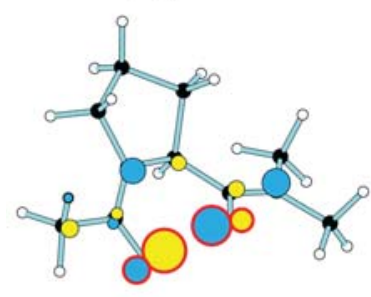

$2 \mathrm{C}^{\cdot+}$

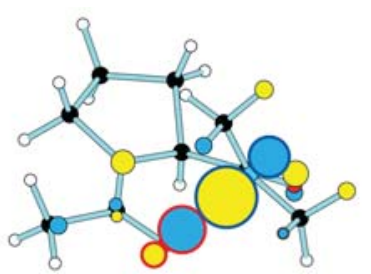

$2 \mathrm{~B}^{\cdot+}$

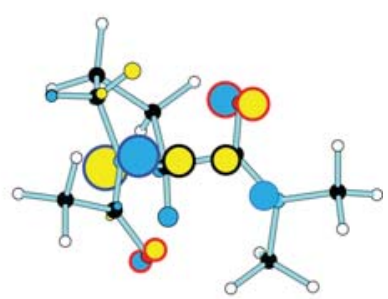

$2 D^{*+}$
Figure 3. Selected conformers of the radical cation of 2 together with their SOMOs. The lobes of the orbitals that are directly involved in the 3-electron interactions are highlighted (red-circled, AOs on oxygen; blue-circled, AOs on nitrogen; black-circled, AOs on carbon).

Table 2. Relative Energies and Ramachandran Angles of the Four Chosen Conformers of the Radical Cation of 2 Calculated with M06-2X/6-31G*

\begin{tabular}{|c|c|c|c|c|}
\hline & $\phi$ & $\psi$ & $\begin{array}{c}\text { relative } \\
\text { energy } \\
(\mathrm{kcal} / \mathrm{mol})\end{array}$ & localizaltion of the SOMO \\
\hline $2 \mathrm{~A}^{\bullet+}$ & -74 & 118 & 0 & hyperconjugative state \\
\hline $2 \mathrm{~B}^{\bullet+}$ & -32 & -21 & 1.4 & $\mathrm{~N}: \therefore \mathrm{O} 2 \mathrm{c}-3 \mathrm{e}$ bond \\
\hline $2 \mathrm{C}^{\bullet+}$ & -40 & 178 & 3.6 & $\mathrm{O} \therefore \mathrm{O} 2 \mathrm{c}-3 \mathrm{e}$ bond \\
\hline $2 \mathrm{D}^{\bullet+}$ & -74 & 120 & 0.5 & $\begin{array}{l}\text { hyperconjugative state with another } \\
\text { envelope conformation of the } \\
\text { proline }\end{array}$ \\
\hline
\end{tabular}

Ramachandran angle $\psi$ increases in $\mathbf{2 \mathbf { A } ^ { \bullet + }}$ compared to $\mathbf{1 A}^{\bullet+}$, approaching the ideal dihedral angle for a polyproline II (PPII) helix $\left(145^{\circ}\right) .^{32}$ Similar to $\mathbf{1 A}^{\bullet+}$, the $\mathrm{C}-\mathrm{C}$ bond involved in the hyperconjugation of the SOMO is longer than a normal $\mathrm{C}_{\alpha}-\mathrm{C}$ bond $(1.68 \AA)$. The $\mathrm{N}, \mathrm{O}$-distance in $2 \mathrm{~B}^{\bullet+}$ $(2.2 \AA)$ and the $\mathrm{O}, \mathrm{O}$-distance in $2 \mathrm{C}^{\bullet+}(2.1 \AA)$ are the same as in the corresponding states of $\mathbf{1}^{\bullet+}$.

AcProProPyrrolidine (Diproline, 3). The next step toward a PPII-helix is the addition of a second proline unit

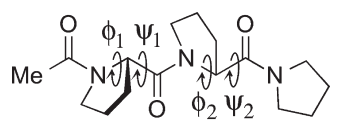

3

to obtain 3, a diproline terminated by an acetyl and a pyrrolidine group (the choice of pyrrolidine to "protect" the C-terminal end of the peptide is motivated by the fact that it resembles a proline unit; thus, the diproline could be considered as a fragment inside a bigger PPII-helix). The conformational space of 3 is so vast that a systematic conformational search becomes very laborious to perform. Instead, the minimal energy structures for the three different electronic states of the radical cations were sought (see Figure 4 and Table 3 ). 

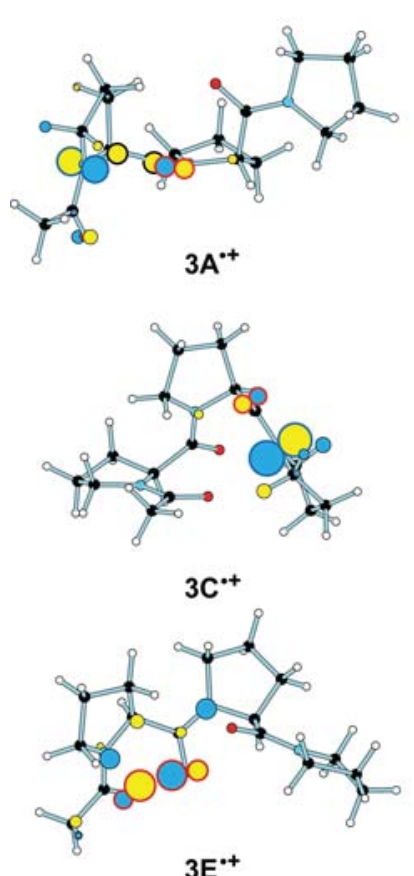

$3 \mathrm{E}^{\cdot+}$
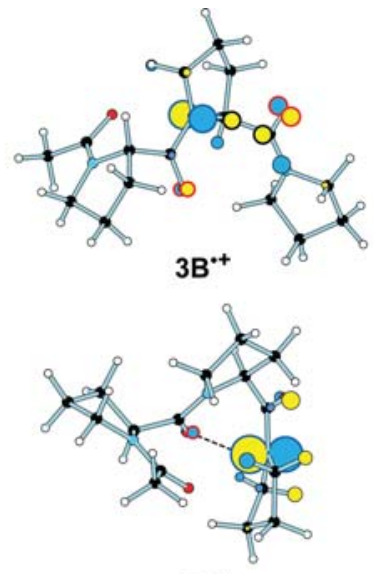

$3 D^{*+}$

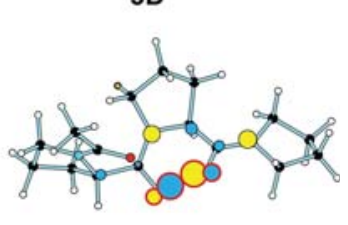

$3 F^{*+}$
Figure 4. Selected conformers of the radical cation of 3 together with their SOMOs. The lobes of the orbitals that are directly involved in the 3-electron interactions are highlighted (red-circled, AOs on oxygen; blue-circled, AOs on nitrogen; black-circled, AOs on carbon).

Table 3. Relative Energies and Ramachandran Angles of Different Chosen Conformers of the Radical Cation of 3 Calculated with M06-2X/6-31G*

\begin{tabular}{|c|c|c|c|c|}
\hline & $\psi_{1}$ & $\psi_{2}$ & $\begin{array}{l}\text { relative energy } \\
\quad(\mathrm{kcal} / \mathrm{mol})\end{array}$ & localization of SOMO \\
\hline $3 \mathrm{~A}^{\bullet+}$ & 158 & 171 & 3.8 & $\begin{array}{l}\text { hyperconjugation at } \\
\mathrm{N} \text {-terminal proline }\end{array}$ \\
\hline $3 \mathrm{~B}^{\circ+}$ & 114 & 119 & 1.7 & $\begin{array}{l}\text { hyperconjugation at } \\
\text { C-terminal proline }\end{array}$ \\
\hline $3 C^{\bullet+}$ & -40 & 85 & 1.8 & $\begin{array}{l}\text { centered on the } \mathrm{N} \text { atom of } \\
\text { pyrrolidine }\end{array}$ \\
\hline $3 \mathrm{D}^{\bullet+}$ & 41 & -33 & 0 & $\begin{array}{l}\text { centered on the } \mathrm{N} \text { atom of } \\
\text { pyrrolidine }\end{array}$ \\
\hline $3 \mathrm{E}^{\bullet+}$ & -173 & 177 & 7.8 & $\begin{array}{l}\mathrm{O}: \mathrm{O} \text { interaction at } \\
\mathrm{N} \text {-terminal proline }\end{array}$ \\
\hline $3 \mathrm{~F}^{\bullet+}$ & -52 & -173 & 13.4 & $\begin{array}{l}\mathrm{O}: \mathrm{O} \text { interaction at } \\
\mathrm{C} \text {-terminal proline }\end{array}$ \\
\hline
\end{tabular}

Two different conformations with a "hyperconjugated SOMO" were found $\left(3 \mathbf{A}^{\bullet+}\right.$ and $\left.3 \mathbf{B}^{\bullet+}\right)$, where the nitrogen lone pairs of the $\mathrm{N}$-terminal and $\mathrm{C}$-terminal proline, respectively, are involved. In both of them, the $\mathrm{C}_{\alpha}-\mathrm{C}$ bond is lengthened, as in $\mathbf{1 A}^{\mathbf{* +}}$.

Interestingly, in the two conformers where a through-space $\mathrm{N}: \mathrm{O}$ interaction is expected to occur $\left(3 \mathrm{C}^{\bullet+}\right.$ and $\left.3 \mathrm{D}^{\circ+}\right)$, the N,O-distance, 2.7 and $2.6 \AA$, respectively, is shorter than the sum of the van der Waals radii of the two atoms but significantly longer than in the corresponding states in $\mathbf{1}^{\bullet+}$ and $2^{\circ+}$. Furthermore, $75-80 \%$ of the spin density is found on the nitrogen atom, while only $1-4 \%$ of it is found on the oxygen atom with which the $\mathrm{N}$ atom interacts through space. Nevertheless, these "N-centered" localized electronic states are surprisingly stable (in fact, $3 \mathrm{D}^{\bullet+}$ represents the global minimum on the potential surface of $3^{\bullet+}$ ).
However, the conformers $3 \mathrm{~A}^{\bullet+}$ to $3 \mathrm{D}^{\bullet+}$ may be accessible during the electron transfer because of their similar relative energies. One can view them as snapshots taken in the course of the electron transfer along the diproline. However, the Ramachandran angles of these four structures are quite different, indicating that large amplitude torsions must occur in order to move from one electronic state to the next. Unfortunately, the transition states and hence the barriers between the different conformers could not be found. As polyproline chains were demonstrated to be still rather flexible, ${ }^{33}$ it might nevertheless be possible that such dramatic conformational changes would be possible.

The lowest energy conformer of $3^{\circ+}$ that shows a $2 \mathrm{c}-3 \mathrm{e}$ $\mathrm{O} \therefore \mathrm{O}$ interaction $\left(3 \mathrm{E}^{\bullet+}\right)$ is found to lie $7.8 \mathrm{kcal} / \mathrm{mol}$ above the global minimum. The probability that such an electronic state plays a role in the electron transfer through PPII-helices is thus quite small. In other words, the "rest and fire" mechanism proposed by Schlag et al. ${ }^{30,31}$ is unlikely to be effective in polyproline chains.

AcProProProPyrrolidine (Triproline, 4). To see whether the trends observed for $3^{\bullet+}$ are valid in a longer peptide, a

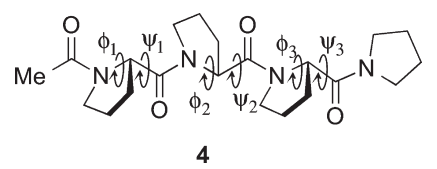

third proline unit was added, to obtain $4^{\bullet+}$. After geometry optimization, the 10 different conformers listed in Table 4 and shown in Figure 5 were obtained. Again we see the four types of radical cation states discussed above ("hyperconjugative state", $\mathrm{N} \therefore \mathrm{O}, \mathrm{N}$-localized, and $\mathrm{O} \therefore \mathrm{O}$ interactions).

It seems that a proper $\mathrm{N} . \mathrm{O}$ interaction within the peptide is not favored $\left(4 \mathrm{D}^{\circ+}\right.$ and $\left.4 \mathrm{E}^{\bullet+}\right)$. However, the transition between a $\mathrm{N}: \mathrm{O}$ delocalized and a $\mathrm{N}$-centered SOMO is continuous. In both cases, the involved nitrogen atom carries around $75 \%$ of the spin density. The largest part of the remaining $25 \%$ is delocalized through space to the next

Table 4. Relative Energies and Ramachandran Angles of Different Chosen Conformers of the Radical Cation of 4 Calculated with M06-2X/6-31G*

\begin{tabular}{|c|c|c|c|c|c|}
\hline & $\psi_{1}$ & $\psi_{2}$ & $\psi_{3}$ & $\begin{array}{c}\text { relative } \\
\text { energy } \\
(\mathrm{kcal} / \mathrm{mol})\end{array}$ & localization of SOMO \\
\hline $4 A^{\bullet+}$ & 164 & 175 & 171 & 4.7 & $\begin{array}{l}\text { hyperconjugation at } \\
\text { N-terminal proline }\end{array}$ \\
\hline $4 \mathrm{~B}^{\bullet+}$ & 113 & 124 & 174 & 1.5 & $\begin{array}{l}\text { hyperconjugation at } \\
\text { central proline }\end{array}$ \\
\hline $4 C^{\bullet+}$ & 122 & 114 & 119 & 1.3 & $\begin{array}{l}\text { hyperconjugation at } \\
\text { C-terminal proline }\end{array}$ \\
\hline $4 D^{\bullet+}$ & 37 & -163 & -39 & 15.0 & $\begin{array}{l}\mathrm{N}: \therefore \mathrm{O} \text { interaction at } \\
\text { central proline }\end{array}$ \\
\hline $4 \mathrm{E}^{\bullet+}$ & -40 & 34 & -169 & 4.0 & $\begin{array}{l}\mathrm{N}: \therefore \mathrm{O} \text { interaction at } \\
\mathrm{C} \text {-terminal proline }\end{array}$ \\
\hline $4 \mathrm{~F}^{\bullet+}$ & 103 & 166 & 167 & 0.0 & $\begin{array}{l}\text { centered on } \mathrm{N} \text { of } \\
\text { central proline }\end{array}$ \\
\hline $4 \mathrm{G}^{\bullet+}$ & 120 & -39 & -32 & 0.2 & $\begin{array}{l}\text { centered on } \mathrm{N} \text { of } \\
\text { pyrrolidine }\end{array}$ \\
\hline $4 \mathrm{H}^{\bullet+}$ & 178 & 178 & 167 & 7.6 & $\begin{array}{l}\mathrm{O} \therefore \mathrm{O} \text { interaction at } \\
\mathrm{N} \text {-terminal proline }\end{array}$ \\
\hline $41^{\bullet+}$ & -44 & -172 & 164 & 11.1 & $\begin{array}{l}\mathrm{O}: \mathrm{O} \text { interaction at } \\
\text { central proline }\end{array}$ \\
\hline $4 \mathrm{~J}^{\bullet+}$ & 118 & -39 & -168 & 11.4 & $\begin{array}{l}\mathrm{O}: \therefore \mathrm{O} \text { interaction at } \\
\text { C-terminal proline }\end{array}$ \\
\hline
\end{tabular}



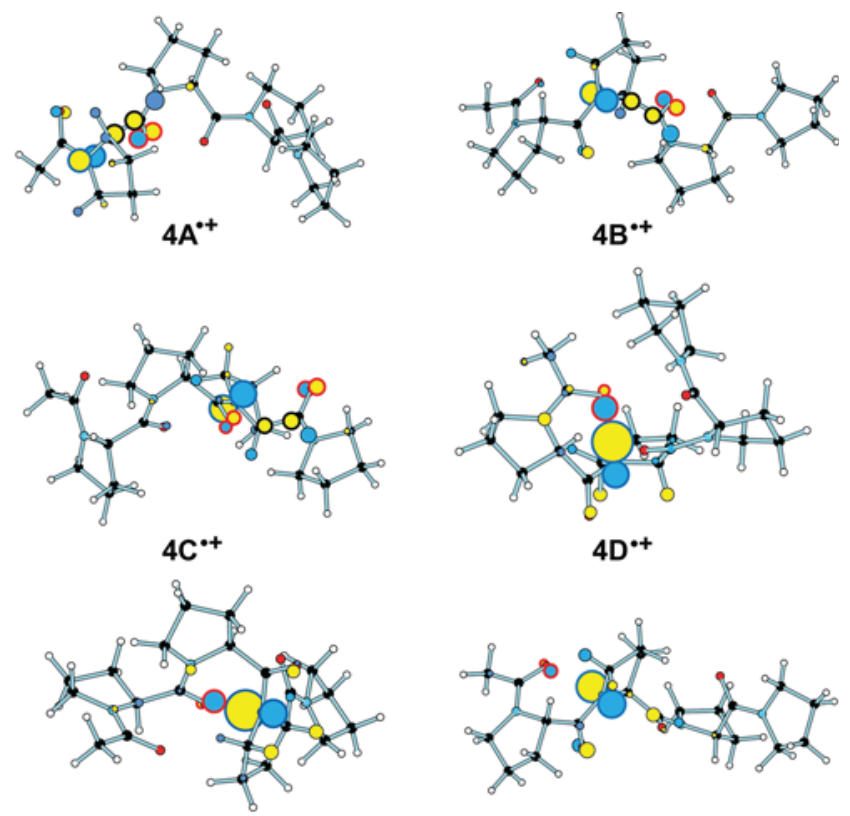

$4 \mathrm{E}^{\cdot+}$

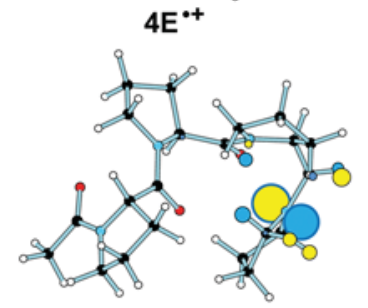

$4 G^{*+}$

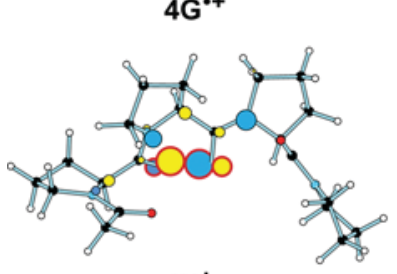

$41^{\bullet+}$

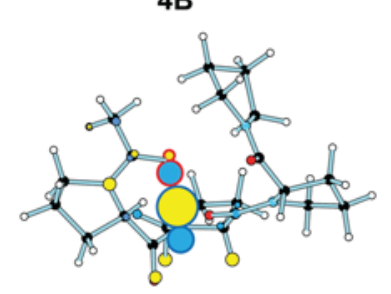

$4 D^{*+}$

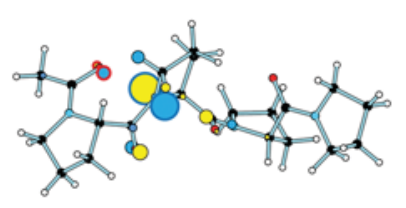

$4 \mathrm{~F}^{\bullet+}$

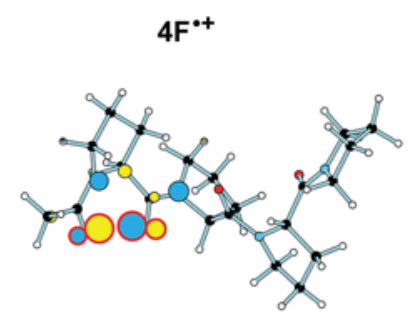

$4 \mathrm{H}^{\circ+}$

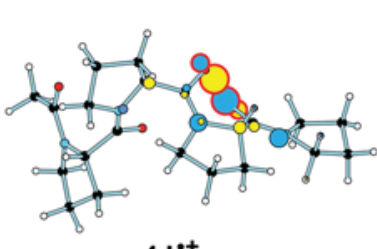

$4 J^{\circ+}$

Figure 5. Selected conformers of the radical cation of 4 together with their SOMOs. The lobes of the orbitals that are directly involved in the 3-electron interactions are highlighted (red-circled, AOs on oxygen; blue-circled, AOs on nitrogen; black-circled, AOs on carbon).

oxygen atom $\left(\mathrm{N}: \mathrm{O}\right.$, conformers $4 \mathrm{D}^{\bullet+}$ and $\left.4 \mathrm{E}^{\bullet+}\right)$ or into the five-membered ring attached to the terminal nitrogen atom $\left(\mathrm{N}\right.$-centered, conformer $\left.\mathbf{4 G ^ { \bullet + }}\right)$. The case of $\mathbf{4} \mathbf{F}^{\bullet+}$ is even more interesting because the remaining $25 \%$ of the spin density is delocalized via hyperconjugation and through space to interact with an oxygen atom. In other words, $\mathbf{4 F ^ { \bullet + }}$ is so low in energy because it benefits from both a small through space and a hyperconjugative through bond interaction between the $\mathrm{N}$ and $\mathrm{O}$ atoms. Another evidence of the partial hyperconjugated character is the length of the involved $\mathrm{C}_{\alpha}-\mathrm{C}$ bond, $1.57 \AA$, which is longer than a usual $\mathrm{C}-\mathrm{C}$ bond but shorter than a typical $\mathrm{C}_{\alpha}-\mathrm{C}$ bond involved in hyperconjugated SOMO.

As in the case of $3^{\bullet+}$, the conformers of $4^{\bullet+}$ showing a $\mathrm{O} \therefore \mathrm{O} 2 \mathrm{c}-3 \mathrm{e}$ bond are too high in energy to be accessible in the course of electron transfer. Easily accessible conformers are those with either a hyperconjugated SOMO $\left(4 \mathrm{~A}^{\bullet+}\right.$ to $4 \mathrm{C}^{\bullet+}$ ) or those having the SOMO centered on a nitrogen $\mathrm{p}$ $\mathrm{AO}\left(4 \mathrm{~F}^{\bullet+}\right.$ and $\left.4 \mathrm{G}^{\bullet+}\right)$. Among these low-energy conformers, $4 \mathrm{~B}^{\bullet+}, \mathbf{4 \mathrm { C } ^ { \bullet + }}$, and $4 \mathrm{~F}^{\bullet+}$ possess dihedral angles $\psi$ that are quite

close to the optimal $145^{\circ}$ needed to form a PPII-helix; i.e., on oxidation of a PPII-helix, minor changes of the dihedral angles can lead to a different electronic state and allow the charge to migrate within the peptide. One should however keep in mind that the change in $\psi$ is not sufficient to access the different electronic states. Indeed, for a hyperconjugated state, the $\mathrm{C}_{\alpha}-$ $\mathrm{C}$ distance has to be increased, and for a N-centered orbital, a twisting around the partial $\mathrm{C}-\mathrm{N}$ double bond of the amide group has to occur.

Figure 5 illustrates the presence of "hyperconjugated" radical cation states localized at the $\mathrm{N}$-terminal $\left(4 \mathrm{~A}^{\circ+}\right)$, at the central proline $\left(4 \mathrm{~B}^{\bullet+}\right)$, and at the $\mathrm{C}$-terminal $\left(4 \mathrm{C}^{\bullet+}\right)$, which all lie within $3.5 \mathrm{kcal} / \mathrm{mol}$, i.e., are thermally accessible, provided that the relatively minor conformational changes that are required to reach them are not hindered. These states, which certainly occur in similar form in longer polyprolines, can serve as backbone-centered stepping stones for the hole transfer through a polyproline.

Hexaproline 5. Wennemers et al. have recently reported the first complete X-ray structure of a hexaproline with a

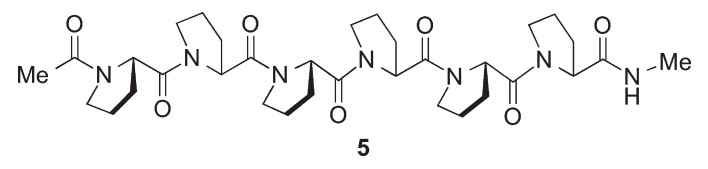

PPII-helix structure, ${ }^{20}$ which allowed us to see how well our calculations reproduce this experimental geometry and what type of radical cation would be formed on oxidation of this hexapeptide. The structure obtained after geometry optimization of the neutral hexaproline is very similar to the $\mathrm{X}$-ray structure (Figure 6a) which shows that M06-2X appears to be well suited to model polyprolines.

If one removes an electron from neutral 5 at its equilibrium structure and reoptimizes the geometry, one obtains the radical cation depicted in Figure $6 \mathrm{~b}$ where the SOMO is centered on the second proline unit, i.e., close to the $\mathrm{N}$ terminus, and is clearly of the hyperconjugative type, with a small additional through space interaction with the acetyl oxygen (about $2 \%$ of the spin density).

As it is impossible to explore all the radical cation states of $5^{\bullet+}$ and their structures, we searched specifically for a state where the charge and spin are close to the C-terminus of $\mathbf{5}$. Figure $6 \mathrm{c}$ shows the SOMO of that state, which is also of the hyperconjugative type. Thus, parts $\mathrm{b}$ and $\mathrm{c}$ of Figure 6 show two snapshots of a hole transfer process through a hexaproline where once the spin resides on the $\mathrm{N}$-terminus and then on the C-terminus (the two states are separated by $4.5 \mathrm{kcal} / \mathrm{mol}$ ). Our explorations of shorter oligoprolines lead us to expect that intermediate states of similar energy (hyperconjugative or N-centered, cf. Figures 4 and 5) exist also along longer polyprolines, states which make it possible for a positive charge and the associated spin to move along polyproline chains with very little activation. Actually, our earlier experiments have shown that the hole transfer through PPII bridges containing three prolines ${ }^{5}$ is faster than calculated for one-step, superexchange reactions where the prolines do not act as hopping stations. ${ }^{34,35}$ It remains to be seen whether such a charge hopping might play a role in electron transport proteins like cytochrome $C{ }^{18}$ or if one can apply charge transfer using collagen fibers, which are built up by triple PPII helices. ${ }^{36}$ The distance influence on the ET rate in polyprolines has been until now only assessed for excess 
a

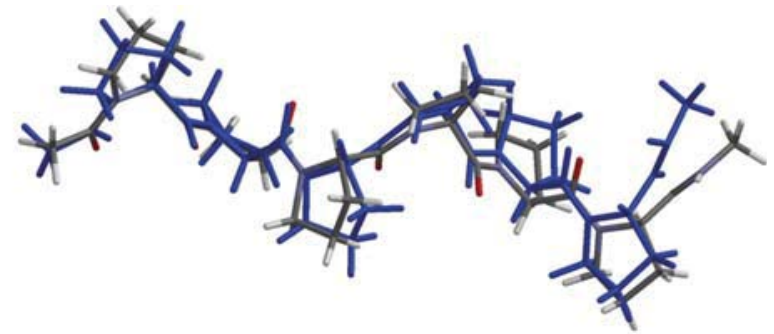

b

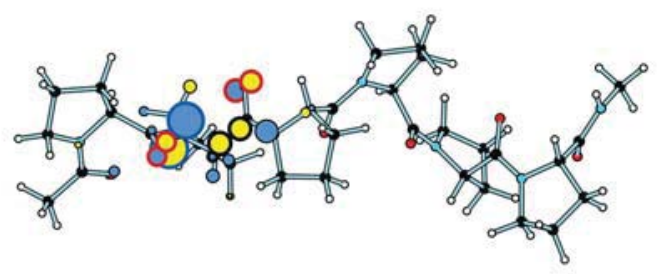

C

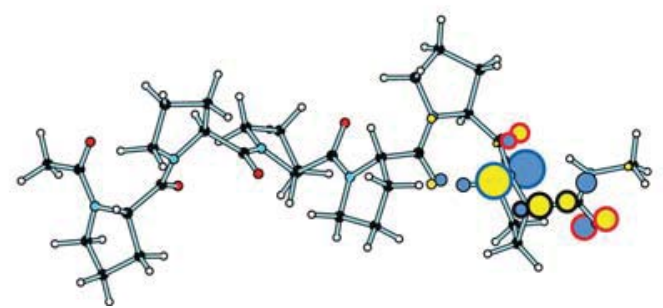

Figure 6. (a) Crystal structure of hexaproline 5 (gray, from ref 18, without the $\mathrm{N}$-terminal $p$-bromophenyl group) superposed on the M06-2X optimized structure (blue); (b) structure and SOMO of the radical cation obtained by removing an electron from neutral 5; (c) structure and SOMO of a radical cation centered at the $\mathrm{N}$-terminus of 5. For the meaning of the circled AOs, see the caption to Figure 1 .

electron transfer. ${ }^{7}$ Analogous experiments for electron hole transfer are still missing.

When an $\alpha$-helix is oxidized, the spin and charge invariably end up at the $\mathrm{C}$-terminus, due to the large dipole moment of these structures. The $\mathrm{C}$-termini of $\alpha$-helices can thus serve as hopping stations for electron hole transfer. ${ }^{15}$ However, exploratory calculations have indicated that hole transport is unlikely to occur along the backbone of an $\alpha$-helix, becausein contrast to PPII helices-the radical cation states that could possibly serve as stepping stones for this process lie much higher in energy than the states localized at the Cterminus. $^{37}$

\section{CONCLUSION}

We have shown that an electron hole can be accommodated on the backbone of a polypeptide in three different ways, represented by three different electronic states of the radical cation. Although these states have been described previously in terms of their spin distribution, they were never identified in terms of their electronic structure. In one of these states, the charge and spin are delocalized between the $\mathrm{N}$ lone pair (or the heteroallylic nonbonding $\mathrm{MO}$ ) of one peptide and the in-plane $\mathrm{p}$-AO of the oxygen of a neighboring peptide through hyperconjugation via the intervening $\mathrm{C}-\mathrm{C} \sigma$-bond, which is significantly lengthened by this interaction.

The second state is stabilized by the formation of a 2 center-3-electron (2c-3e) N.:O-bond between an $\mathrm{N}$ lone pair that interacts through space with the in-plane p-AO of the oxygen that is five bonds removed (in some such cases, the spin and charge are mainly localized on the $\mathrm{N}$ atom). The third state features a $2 \mathrm{c}-3 \mathrm{e}$ O $\therefore$ O-bond between the in-plane p-AOs of the $\mathrm{O}$ atoms of two neighboring peptide units. All three states are significantly more stable than those attained by ionization of an isolated amide, which may make them amenable to serve as hopping stations in charge transfer processes across peptides. The relative energies of the three states depend very much on the nature of the peptide which dictates how easily the conformations that are needed to form these states can be attained.

In PPII-helices of polyprolines, the Ramachandran angles are nearly ideal for the formation of the above-described "hyperconjugative" radical cation states, which is why such states can readily be formed in such peptides, and are in fact usually among the most stable ones, together with the $\mathrm{N}: \mathrm{O}$ bound or $\mathrm{N}$-centered states (in polyprolines, the $\mathrm{O}: \mathrm{O}$-bound states are higher in energy and cannot compete). Our investigations on di-, tri, and hexaprolines showed that states where the radical cation is localized near the $\mathrm{N}$-terminus and the C-terminus, respectively, as well as intermediate states localized on central parts of the polyproline backbone lie all within ca. $4 \mathrm{kcal} / \mathrm{mol}$. Our studies of oligoprolines lead us to predict that the charge and spin formed on one-electron oxidation of such peptides can migrate from one end to the other with a very small energy of activation.

\section{ASSOCIATED CONTENT}

\section{S Supporting Information}

Full refs 9, 12, and 23 and Figures $S 1$ and S2 as well as Tables S1 and S2 that are referenced in the main text of the paper.

\section{AUTHOR INFORMATION}

\section{Corresponding Authors}

*E-mail: thomas.bally@unifr.ch.

*E-mail: bernd.giese@unifr.ch.

\section{Notes}

The authors declare no competing financial interest.

\section{ACKNOWLEDGMENTS}

The authors wish to thank the Swiss National Foundation (SNF) for the financial support (Grant No. 200020_143410) and Helma Wennemers (ETH Zürich) for fruitful discussions.

\section{REFERENCES}

(1) Cordes, M.; Giese, B. Electron Transfer in Peptides and Proteins. Chem. Soc. Rev. 2009, 38, 892-901.

(2) Giese, B.; Eckhardt, S.; Lauz, M. Electron Transfer in Peptides and Proteins. In Encyclopedia of Radicals in Chemistry, Biology and Materials; Chatgilialoglu, C., Studer, A., Eds.; Wiley: Chichester, U.K., 2012; pp 1475-1499.

(3) Stubbe, J.; Nocera, D. G.; Yee, C. S.; Chang, M. C. Y. Radical Initiation in the Class I Ribonucleotide Reductase: Long-Range Proton-Coupled Electron Transfer? Chem. Rev. 2003, 103, 21672201.

(4) Cordes, M.; Kottgen, A.; Jasper, C.; Jacques, O.; Boudebous, H.; Giese, B. Influence of Amino Acid Side Chains on Long-Distance Electron Transfer in Peptides: Electron Hopping Via "Stepping Stones". Angew. Chem., Int. Ed. 2008, 47, 3461-3463.

(5) Gao, J. A.; Müller, P.; Wang, M.; Eckhardt, S.; Lauz, M.; Fromm, K. M.; Giese, B. Electron Transfer in Peptides: The Influence of Charged Amino Acids. Angew. Chem., Int. Ed. 2011, 50, 1926-1930. 
(6) Arikuma, Y.; Nakayama, H.; Morita, T.; Kimura, S. Electron Hopping over 100 Angstrom Along an Alpha Helix. Angew. Chem., Int. Ed. 2010, 49, 1800-1804.

(7) Malak, R. A.; Gao, Z. N.; Wishart, J. F.; Isied, S. S. Long-Range Electron Transfer across Peptide Bridges: The Transition from Electron Superexchange to Hopping. J. Am. Chem. Soc. 2004, 126, $13888-13889$.

(8) Giese, B.; Wang, M.; Gao, J.; Stoltz, M.; Muller, P.; Graber, M. Electron Relay Race in Peptides. J. Org. Chem. 2009, 74, 3621-3625.

(9) Shih, C.; Museth, A. K.; Abrahamsson, M.; Blanco-Rodriguez, A. M.; Di Bilio, A. J.; Sudhamsu, J.; Crane, B. R.; Ronayne, K. L.; Towrie, M.; Vlcek, A.; et al. Tryptophan-Accelerated Electron Flow through Proteins. Science 2008, 320, 1760-1762.

(10) Wang, M.; Gao, J.; Muller, P.; Giese, B. Electron Transfer in Peptides with Cysteine and Methionine as Relay Amino Acids. Angew. Chem., Int. Ed. 2009, 48, 4232-4234.

(11) Chung, W. J.; Ammam, M.; Gruhn, N. E.; Nichol, G. S.; Singh, W. P.; Wilson, G. S.; Glass, R. S. Interactions of Arenes and Thioethers Resulting in Facilitated Oxidation. Org. Lett. 2009, 11, 397-400.

(12) Glass, R. S.; Hug, G. L.; Schöneich, C.; Wilson, G. S.; Kuznetsova, L.; Lee, T. M.; Ammam, M.; Lorance, E.; Nauser, T.; Nichol, G. S.; et al. Neighboring Amide Participation in Thioether Oxidation: Relevance to Biological Oxidation. J. Am. Chem. Soc. 2009, 131, 13791-13805.

(13) Glass, R. S.; Schöneich, C.; Wilson, G. S.; Nauser, T.; Yamamoto, T.; Lorance, E.; Nichol, G. S.; Ammam, M. Neighboring Pyrrolidine Amide Participation in Thioether Oxidation. Methionine as a "Hopping" Site. Org. Lett. 2011, 13, 2837-2839.

(14) Monney, N. P. A.; Bally, T.; Bhagavathy, G. S.; Glass, R. S. Spectroscopic Evidence for a New Type of Bonding between a Thioether Radical Cation and a Phenyl Group. Org. Lett. 2013, 15, 4932-4935.

(15) Chen, X. H.; Zhang, L. B.; Zhang, L.; Sun, W. M.; Zhang, Z. W.; Liu, H. Y.; Bu, Y. X.; Cukier, R. I. Alpha-Helix C-Terminus Acting as a Relay to Mediate Long-Range Hole Migration in Proteins. J. Phys. Chem. Lett. 2010, 1, 1637-1641.

(16) Lauz, M.; Eckhardt, S.; Fromm, K. M.; Giese, B. The Influence of Dipole Moments on the Mechanism of Electron Transfer through Helical Peptides. Phys. Chem. Chem. Phys. 2012, 14, 13785-13788.

(17) Zhang, R.; Liu, J.; Yang, H.; Wang, S.; Zhang, M.; Bu, Y. Computational Insights into the Charge Relaying Properties of BetaTurn Peptides in Protein Charge Transfers. ChemPhysChem 2014, 16, 436-446.

(18) Adzhubei, A.; Sternberg, M.; Makarov, A. A. Polyproline-Ii Helix in Proteins: Structure and Function. J. Mol. Biol. 2013, 425, $2100-2132$.

(19) A typical example of a polyproline PPII helix is shown in Figure 6.

(20) Wilhelm, P.; Lewandowski, B.; Trapp, N.; Wennemers, H. A Crystal Structure of an Oligoproline PPII-Helix, at Last. J. Am. Chem. Soc. 2014, 136, 15829-15832.

(21) Kuemin, M.; Schweizer, S.; Ochsenfeld, C.; Wennemers, H. Effects of Terminal Functional Groups on the Stability of the Polyproline Ii Structure: A Combined Experimental and Theoretical Study. J. Am. Chem. Soc. 2009, 131, 15474-15482.

(22) Monney, N. P.-A.; Bally, T.; Giese, B. Proline as a Charge Stabilizing Amino Acid in Peptide Radical Cations. J. Phys. Org. Chem. 2015, 28, 347-353.

(23) Frisch, M. J.; Trucks, G. W.; Schlegel, H. B.; Scuseria, G. E.; Robb, M. A.; Cheeseman, J. R.; Scalmani, G.; Barone, V.; Mennucci, B.; Petersson, G. A.; et al. Gaussian 09; Gaussian, Inc.: Wallingford, CT, 2009.

(24) Zhao, Y.; Truhlar, D. G. Density Functionals with Broad Applicability in Chemistry. Acc. Chem. Res. 2008, 41, 157-167.

(25) Curtiss, L. A.; Redfern, P. C.; Raghavachari, K. Gaussian-4 Theory. J. Chem. Phys. 2007, 126, 084108-1-084108-16.

(26) Olkhov, R. V.; Bally, T. Moplot V. 1.86; http://www-chem. unifr.ch/tb/moplot/moplot.html (accessed Dec 29, 2014).
(27) Chen, X. H.; Zhang, L.; Wang, Z. P.; Li, J. L.; Wang, W.; Bu, Y. X. Relay Stations for Electron Hole Migration in Peptides: Possibility for Formation of Three-Electron Bonds Along Peptide Chains. J. Phys. Chem. B 2008, 112, 14302-14311.

(28) Gil, A.; Sodupe, M.; Bertran, J. Influence of Ionization on the Conformational Preferences of Peptide Models. Ramachandran Surfaces of N-Formyl-Glycine Amide and N-Formyl-Alanine Amide Radical Cations. J. Comput. Chem. 2009, 30, 1771-1784.

(29) Bushwell, C. H.; O’Neil, J. W.; Halford, M. H.; Bissett, F. H. Barrier to Conformational Isomerism in an N-Acetylpyrrolidine by Total Nuclear Magnetic Resonance Line Shape Analysis and Direct Thermal Equilibration. J. Am. Chem. Soc. 1971, 93, 1471-1473.

(30) Schlag, E. W.; Sheu, S. Y.; Yang, D. Y.; Selzle, H. L.; Lin, S. H. Charge Conductivity in Peptides: Dynamic Simulations of a Bifunctional Model Supporting Experimental Data. Proc. Natl. Acad. Sci. U.S.A. 2000, 97, 1068-1072.

(31) Schlag, E. W.; Sheu, S. Y.; Yang, D. Y.; Selzle, H. L.; Lin, S. H. Distal Charge Transport in Peptides. Angew. Chem., Int. Ed. 2007, 46, 3196-3210.

(32) Adzhubei, A. A.; Sternberg, M. J. E. Left-Handed PolyprolineIi Helices Commonly Occur in Globular-Proteins. J. Mol. Biol. 1993, 229, 472-493.

(33) Schuler, B.; Lipman, E. A.; Steinbach, P. J.; Kumke, M.; Eaton, W. A. Polyproline and the "Spectroscopic Ruler" Revisited with Single-Molecule Fluorescence. Proc. Natl. Acad. Sci. U.S.A. 2005, 102, 2754-2759.

(34) Heck, A.; Woiczikowski, P. B.; Kubar, T.; Welke, K.; Niehaus, T.; Giese, B.; Skourtis, S.; Elstner, M.; Steinbrecher, T. B. Fragment Orbital Based Description of Charge Transfer in Peptides Including Backbone Orbitals. J. Phys. Chem. B 2014, 118, 4261-4272.

(35) Heck, A.; Woiczikowski, P. B.; Kubar, T.; Giese, B.; Elstner, M.; Steinbrecher, T. B. Charge Transfer in Model Peptides: Obtaining Marcus Parameters from Molecular Simulation. J. Phys. Chem. B 2012, 116, 2284-2293.

(36) Shoulders, M. D.; Raines, R. T. Collagen Structure and Stability. Annu. Rev. Biochem. 2009, 78, 929-958.

(37) Monney, N. P.-A.; Bally, T. Unpublished results. 